Syntax Literate: Jurnal Ilmiah Indonesia p-ISSN: 2541-0849

e-ISSN: 2548-1398

Vol. 6, No. 10, Oktober 2021

\title{
ANALISIS BAHAYA DAN RESIKO PADA PENGERJAAN PEMASANGAN GENTENG DI PT. BUMI RAJAWALI SENTOSA MENGGUNAKAN METODE JOB HAZARD ANALYSIS
}

\section{Bhuana Satria Gigantara}

Universitas Singaperbangsa Karawang Jawa Barat, Indonesia

Email: 1610631140032@student.unsika.ac.id

\begin{abstract}
Abstrak
Kegiatan produksi akan kearah yang lebih baik apabila sebuah perusahaan tidak hanya dituntut untuk memfokuskan dirinya pada faktor mesin dan bahan baku saja, namun sumber daya manusia dalam hal ini keselamatan karyawan juga menjadi hal utama yang harus diperhatikan. Tujuan penelitian ini terbagi menjadi dua, yaitu: 1). Penyebab kecelakaan bisa diketahui oleh metode JHA agar jumlah kecelakaan kerja dapat berkurang. 2). Dapat menjelasakan pengaruh JHA pada suatu sektor elemen proses yg terjadi kecelakaan kerja dapat diminialisir. Dalam menyelesaikan permasalahan diperlukan suatu metode pemecahan masalah. Adapun langkah langkah metodologi pemecahan masalah adalah sebagai berikut: 1). Studi Pustaka yaitu, dengan mempelajari buku - buku yang berkaitan dengan permasalahan dan mempelajari literatur yang diperoleh dari perusahaan. 2). Studi Lapangan yaitu, dengan melakukan pengamatan langsung dengan staff yang berkaitan dan operator yang bersangkutan sesuai proses - proses yang diterapkan pada perusahaan tersebut. Hasil Safety Indicator mengurangi tingkat kecelakaan kerja serta pengujian korelasi terhadap implementasi JHA pada pemasangan genteng terhadap data jumlah kecelakaan kerja adalah sebesar 0.999 yang mengindikasikan adanya hubungan yang sangat kuat antara implementasi JHA terhadap penurunan data kecelakaan kerja.
\end{abstract}

Kata Kunci: job hazard analysis; correlation coefficient; K3

\section{Abstract}

Production activities will be better if a company is not only required to focus itself on machine factors and raw materials, but human resources in this case employee safety is also the main thing that must be considered. The purpose of this study is divided into two, namely: 1). The cause of the accident can be known by the JHA method so that the number of work accidents can be reduced. 2). Can explain the influence of JHA on a sector of process elements that occur work accidents can be minimized. Solving a problem requires a method of solving the problem. The steps of problem-solving methodology are as follows: 1). Literature studies that are, by studying books related to problems and studying literature obtained from companies. 2). Field Studies that is, by making direct observations with the relevant staff and the operators concerned according to the processes applied to the company. The safety indicator results reduced the rate of work accidents and correlation testing of JHA implementation on tile installation to work accident

$\begin{array}{ll}\text { How to cite: } & \text { Gigantara. B.S (2021) Analisis Bahaya dan Resiko pada Pengerjaan Pemasangan Genteng. Syntax } \\ & \text { Literate: Jurnal Ilmiah Indonesia, 6(10). http://dx.doi.org/10.36418/ Syntax-Literate.v6i10.4347 } \\ \text { E-ISSN: } & \text { 2548-1398 } \\ \text { Published by: } & \text { Ridwan Institute }\end{array}$


number data was 0.999 which indicates a very strong relationship between JHA implementation and decreased work accident data.

Keywords: job hazard analysis; correlation coefficient; K3

Received: 2021-09-20; Accepted: 2021-10-05; Published: 2021-10-20

\section{Pendahuluan}

Kegiatan produksi akan kearah yang lebih baik apabila sebuah perusahaan tidak hanya dituntut untuk memfokuskan dirinya pada faktor mesin dan bahan baku saja, namun sumber daya manusia dalam hal ini keselamatan karyawan juga menjadi hal utama yang harus diperhatikan (Syarif, 2010). Selama bekerja para pekerja dihadapi oleh berbagai risiko yang memungkinkan terjadinya kecelakaan kerja. Faktor penyebab suatu kecelakaan dapat dikelompokkan menjadi dua kelompok (Sugiyanto \& Santi, 2015). Pertama, kondisi berbahaya (unsafe condition), yaitu yang tidak aman dari mesin, peralatan, bahan, dari lingkungan kerja, proses kerja, sifat pengerjaan dan cara kerja. Kedua, perbuatan berbahaya (unsafe action) yaitu perbuatan berbahaya dari manusia yang dapat terjadi karena kurangnya pengetahuan dan keterampilan, cacat tubuh yang tidak terlihat (bodily defect), ketelitian dan kelemahan daya tahan tubuh, serta sikap dan perilaku kerja yang tidak baik (Marbun, Puspitasari, \& Budiawan, 2015). PT. Bumi Rajawali Sentosa merupakan salah satu perusahaan yang bergerak di bidang konstruksi Kasus kecelakaan kerja yang terjadi pada rentang waktu Bulan Februari Maret 2020 cukup tinggi dan cenderung meningkat sehingga di butuhkan pengendalian pada proses pekerjaan agar dapat meminimalisir jumlah kejadian kecelakaan kerja (Dharmawirawan \& Modjo, 2012).

Menurut (Phuspa \& Rudyarti, 2017) bahwa pengendalian risiko dilakukan terhadap seluruh bahaya yang ditemukan dalam proses identifikasi bahaya dan mempertimbangkan peringkat risiko untuk menemukan prioritas dan cara pengendaliannya. Selanjutnya, dalam menentukan pengendalian harus mempertimbangkan hirarki pengendalian mulai dari eliminasi, substitusi, pengendalian teknis, administratif dan penyediaan alat keselamatan yang disesuaikan dengan kondisi organisasi, ketersedian biaya, biaya operasional, faktor manusia dan lingkungan. Pengendalian risiko merupakan langkah menentukan dalam keseluruhan manajemen risiko.

Teknik Semi Proaktif disebut juga belajar dari pengalaman orang lain karena kita tidak perlu mengalaminya sendiri. Teknik ini lebih baik karena tidak perlu mengalami sendiri setelah itu baru mengetahui adanya bahaya (Ramdan \& Rahman, 2018). Namun teknik ini juga kurang efektif (Rosdiana, Anggraeni, \& Umyati, 2017) karena tidak semua bahaya telah diketahui atau pernah menimbulkan dampak kejadian kecelakaan, tidak semua kejadian dilaporkan atau diinformasikan kepada pihak lain untuk diambil sebagai pelajaran, dan kecelakaan telah terjadi yang berarti tetap menimbulkan kerugian, walaupun menimpa pihak lain. 
Identifikasi bahaya merupakan langkah awal dalam mengembangkan manajemen risiko K3. Identifikasi bahaya adalah untuk menjawab pertanyaan apa potensi bahaya yang dapat terjadi atau menimpa organisasi/perusahaan dan bagaimana terjadinya. Identifikasi bahaya adalah upaya sistematis untuk mengetahui adanya bahaya dalam aktivitas organisasi (Haidi \& Abdullah, 2020). Sejalan dengan proses manajemen risiko, menurut (Li, Zhang, \& Liang, 2016) bahwa mensyaratkan prosedur identifikasi hazard dan penilaian risiko sebagai berikut: 1). Mencakup seluruh kegiatan organisasi baik kegiatan rutin maupun non rutin. Tujuannya agar semua hazard yang ada dapat diidentifikasi dengan baik, termasuk hazard yang dapat timbul dalam kegiatan non rutin seperti pemeliharaan, proyek pengembangan, dan lainnya. 2). Perilaku manusia, kemampuan, dan faktor manusia lainnya. Faktor manusia harus dipertimbangkan ketika melakukan identifikasi hazard dan penialaian risiko. Manusia dengan perilaku, kemampuan, pengalaman, latar belakang pendidikan, dan sosial memiliki kerentanan terhadap keselamatan. Perilaku yang kurang baik mendorong terjadinya tindakan berbahaya yang dapat mengarah terjadinya kecelakaan kerja. 3). Identifikasi semua hazard yang berasal dari luar tempat kerja karena dapat menimbulkan efek terhadap kesehatan dan keselamatan manusia yang berada di tempat kerja.

Job Hazard Analysis (Swartz, 2002) adalah perangkat penting dalam keseluruhan sistem manajemen yang akan membantu pencegah cidera dan secara spesifik menetapkan prosedur kerja lebih efektif yang memberikan nilai kepada organisasi. (JHA is an essential tool in the overall management system that will help to prevent injuries and in turn establish more effective job procedures that provide value to the organization (Istanti, Tama, \& Azlia, 2019). Job Hazard Analysis adalah sebuah teknik yang fokus pada tugas-tugas pekerjaan sebagai cara untuk mengidentifikasi bahaya sebelum timbul. JOHANA fokus dengan hubungan antara pekerja, tugas peralatan dan lingkungan kerja (Martaningtyas \& Ariesyady, 2018).

Kecelakaan kerja yang kerap terjadi pada PT. Bumi Rajawali Sentosa mengalami peningkatan akibat tidak adanya tindakan dalam bidang keselamatan kerja dan dapat dibandingkan disaat periode penelitian pada Tabel 1 dibawah ini.

Tabel 1

Jumlah Kejadian Kecelakaan Kerja di PT Bumi Rajawali Sentosa Bulan Januari 2020

\begin{tabular}{llccccc}
\hline \multicolumn{7}{c}{ Bulan Januari 2020 } \\
\cline { 3 - 7 } No & \multirow{2}{*}{ Jenis Kecelakaan } & Jumlah & Luka Ringan & $\begin{array}{l}\text { Luka } \\
\text { Berat }\end{array}$ & Cacat & Kematian \\
\hline 1 & Tergelincir & 7 & 4 & 3 & 0 & 0 \\
\hline 2 & Tertimpa Material & 9 & 4 & 5 & 0 & 0 \\
\hline 3 & Tergores & 98 & 48 & 50 & 0 & 0 \\
\hline 4 & Terkilir & 39 & 10 & 29 & 0 & 0 \\
\hline 5 & Cedera & 17 & 10 & 7 & 0 & 0 \\
\hline 6 & Terjepit Material & 24 & 7 & 17 & 0 & 0 \\
\hline 7 & Terjatuh & 27 & 7 & 20 & 0 & 0 \\
\hline
\end{tabular}




\begin{tabular}{|c|c|c|c|c|c|c|c|c|}
\hline 8 & Patah Tulang & & 0 & & 0 & 0 & 0 & 0 \\
\hline 9 & Iritasi Mata & & 31 & & 8 & 23 & 0 & 0 \\
\hline Tota & & & 307 & & 273 & 32 & 0 & 0 \\
\hline \multicolumn{9}{|c|}{ Bulan Februari - Maret } \\
\hline \multirow[b]{2}{*}{ No } & & & & & kibat & & \multirow[b]{2}{*}{ Periode } & \\
\hline & Jenis Kecelakaan & Jumlah & $\begin{array}{l}\text { Luka } \\
\text { Ringan }\end{array}$ & $\begin{array}{l}\text { Luka } \\
\text { Berat }\end{array}$ & Cacat & Kematian & & \\
\hline 1 & Tergelincir & 18 & 14 & 4 & 0 & 0 & \multirow{4}{*}{ Februari } & \\
\hline 2 & Tertimpa Material & 12 & 7 & 5 & 0 & 0 & & \\
\hline 3 & Tergores & 127 & 125 & 2 & 0 & 0 & & \\
\hline 4 & Terkilir & 48 & 39 & 9 & 0 & 0 & & \\
\hline 5 & Cedera & 24 & 13 & 9 & 0 & 0 & \multirow{6}{*}{ Maret } & \\
\hline 6 & Terjepit Material & 36 & 36 & 0 & 0 & 0 & & \\
\hline 7 & Terjatuh & 36 & 2 & 3 & 0 & 0 & & \\
\hline 8 & Patah Tulang & 0 & 0 & 0 & 0 & 0 & & \\
\hline 9 & Iritasi Mata & 37 & 37 & 0 & 0 & 0 & & \\
\hline Tota & & 307 & 273 & 32 & 0 & 0 & & \\
\hline
\end{tabular}

Sumber: PT. Bumi Rajawali Sentosa

Dari permasalahan diatas, maka perlu dilakukakannya penelitian di PT. Bumi Rajawali Sentosa dengan judul penelitian yaitu: "Analisis Bahaya Dan Resiko Pada Pengerjaan Pemasangan Genteng di PT. Bumi Rajawali Sentosa Menggunakan Metode Job Hazard Analysis (Studi Kasus Pembangunan Perumahan Bumi Tirta Nirwana)”.

Hasil dari penelitian ini dapat menjadi informasi dan rekomendasi kepada perusahaan dan mitra kerja sebagai bahan pertimbangan memperbaiki dalam hal identifikasi bahaya dan penanganannya di tempat kerja yang dilakukan pada PT. Bumi Rajawali Sentosa. Hasil dari penelitian ini dapat dijadikan sebagai bahan referensi tambahan bagi civitas akademik Prodi Teknik Industri Universitas Singaperbangsa Karawang. Terutama mengenai pengaruh penggunaan metode JHA dalam menangani kecelakaan kerja. Hasil penelitian ini dapat dijadikan bahan referensi bagi peneliti lain yang akan melakukan penelitian sejenis terkait level of risk serta alat pelindung diri di tempat kerja. Tujuan penelitian ini terbagi menjadi dua, yaitu penyebab kecelakaan bisa diketahui oleh metode JHA agar jumlah kecelakaan kerja dapat berkurang. Dapat menjelasakan pengaruh JHA pada suatu sektor elemen proses yg terjadi kecelakaan kerja dapat diminialisir

\section{Metode Penelitian}

Data-data yang telah dikumpulkan kemudian akan diolah sesuai dengan kebutuhan dan metode yang digunakan.

1. Penentuan metode

Di tahap ini dilakukan penentuan metode yang ingin digunakan dan mempersiapkan studi terkait baik dari segi kesiapan maupun kondisi yang ada pada lapangan, mengkondisikan sebaik mungkin sehingga tidak ada terjadinya kesalahan pada saat penentuan metode.

2. Pengumpulan data 
Data diperoleh dengan melalui metode pengamatan langsung (Dasar \& Operasional, 1988) dan memakai tahapan - tahapan yang sistematis sehingga didapatkan data yang akurat dan relevan.

3. Deskripsi Elemen Kerja

Mendeskripsikan elemen kerja pada pekerjaan yang akan dibuatkan analisa resiko bahaya pada pekerjaan tersebut untuk dianalisa di tahap selanjutnya yang dipastikan terlebih dahulu kebenarannya setiap ingin melanjutkan pada tahapan berikutnya.

4. Pembuatan JHA (Job Hazard Analysis)

Pembuatan form JHA yang di buat sesuai dengan kondisi lapangan yang ada menyusun nya dengan komputerisasi berdasarkan hasil pengolahan sebelumnya.

5. Penentuan Level of Risk

Dari data identifikasi JHA maka dapat ditentukan Level of Risk yaitu tingkat resiko yang didapatkan yang dapat di identifikasi melalui angka yang diperoleh pada masing masing elemen kerja.

6. Penentuan Safety Indication

Analisis safety indication sesuai dengan permasalahan yang diperoleh sehingga didapatkan APD yang sesuai dengan perasalahan yang ada.

7. Uji Korelitas

Uji pengaruh antara implementasi JHA terhadap Keselamatan dan kesehatan kerja berdasarkan nilai yang didapatkan dari hasil implementasi lalu dibandingkan gap atau selisih yang ada sehingga dapat dilakukan pengolahan data pada tahap ini.

\section{Hasil dan Pembahasan}

\section{A. Data Khusus}

1. Data Kecelakaan Kerja Februari - Maret 2020

PT. Bumi Rajawali Sentosa mememiliki jumlah kecelakaan kerja yang cukup besar dan butuh penanganan pada bidang pekerjaan pemasangan genteng yang dapat dilihat di tabel Tabel 2 dibawah ini:

Tabel 2

Data Kecelakaan Kerja Februari - Maret 2020

\begin{tabular}{|c|c|c|c|c|c|c|c|}
\hline \multicolumn{8}{|c|}{ Bulan Februari - Maret } \\
\hline \multirow{2}{*}{ No } & \multirow{2}{*}{ Jenis Kecelakaan } & \multirow{2}{*}{ Jumlah } & \multicolumn{4}{|c|}{$\begin{array}{r}\text { Akibat } \\
\end{array}$} & \multirow{2}{*}{ Periode } \\
\hline & & & Luka Ringan & Luka Berat & Cacat & Kematian & \\
\hline 1 & Tergelincir & 18 & 14 & 4 & 0 & 0 & \multirow{4}{*}{ Februari } \\
\hline 2 & Tertimpa Material & 12 & 7 & 5 & 0 & 0 & \\
\hline 3 & Tergores & 127 & 125 & 2 & 0 & 0 & \\
\hline 4 & Terkilir & 48 & 39 & 9 & 0 & 0 & \\
\hline 5 & Cedera & 24 & 13 & 9 & 0 & 0 & \multirow{5}{*}{ Maret } \\
\hline 6 & Terjepit Material & 36 & 36 & 0 & 0 & 0 & \\
\hline 7 & Terjatuh & 36 & 2 & 3 & 0 & 0 & \\
\hline 8 & Patah Tul & 0 & 0 & 0 & 0 & 0 & \\
\hline 9 & Iritasi $\mathrm{M} \varepsilon$ & 37 & 37 & 0 & 0 & 0 & \\
\hline
\end{tabular}




\begin{tabular}{llllll|}
\hline Total & 307 & 273 & 32 & 0 & 0 \\
\hline
\end{tabular}

Sumber: PT. Bumi Rajawali Sentosa

Dilihat dari Tabel bahwa data kecelakaan kerja luka ringan menunjukan jumlah nilai sebanyak 273, luka berat sebanyak 32, cacat sebanyak 0 , kematian dengan jumlah 0 dengan total kecelakaan kerja yang terjadi adalah sebanyak 307 . Untuk total karyawan yang ada di PT. Rajawali Sentosa adalah sebanyak 158 orang.

2. Data Elemen Pekerjaan

Dilihat di Tabel 3 berdasarkan pengamatan yang dilakukan di PT. Bumi Rajawali Sentosa bahwa untuk dapat melakukan pengolahan data dengan JHA, perlu dilakukannya identifikasi elemen-elemen pekerjaan yang akan dianalisis.

Tabel 3

Elemen Pekerjaan

\begin{tabular}{cc}
\hline No & Langkah-Langkah Pengerjaan \\
\hline 1 & Menentukan Posisi Tangga \\
\hline 2 & Memasang Tangga \\
\hline 3 & Periksa Tangga \\
\hline 4 & Menaiki Tangga \\
\hline 5 & Menuju titik Pemasangan \\
\hline 6 & Mengangkat Genteng \\
\hline 7 & Menentukan Titik Pemasangan Genteng \\
\hline 8 & Mengambil Genteng \\
\hline 9 & Memasang Genteng \\
\hline 10 & Mengangkat Adukan Semen \\
\hline 11 & Mengambil Adukan Semen \\
\hline 12 & Menyemen Genteng yang Sudah dipasang \\
\hline 13 & Mengecek Kerapatan Semen pada genteng \\
\hline \multicolumn{3}{c}{ Sumber: PT. Bumi Rajawali Sentosa }
\end{tabular}

Berdasarkan Tabel 3 bahwa hasil identifikasi pekerjaan yang hendak dianalisa memiliki 13 tahapapan pekerjaan dari awal kegiatan sampai dengan akhir kegiatan.

\section{B. Pengolahan Data}

1. Analisis dan Usulan Perbaikan dengan JHA (Job Hazard Analysis)

Data elemen kerja yang sudah di deskripsikan secara rinci maka dilakukan penyusunan JHA untuk mengidentifikasi potential hazard dan safety indication serta level of risk. 
Analisis Bahaya dan Resiko pada Pengerjaan Pemasangan Genteng Di PT. Bumi Rajawali Sentosa Menggunakan Metode Job Hazard Analysis

Tabel 4

Form JHA

\begin{tabular}{|c|c|c|c|c|c|c|c|}
\hline \multicolumn{8}{|c|}{ JOB HAZARD ANALYSIS } \\
\hline \multicolumn{2}{|c|}{ Nama Pekerjaan } & \multicolumn{2}{|c|}{ Memasang Genteng } & \multicolumn{2}{|l|}{ Nomor JHA } & \multicolumn{2}{|c|}{ 01.JHA } \\
\hline PIC & & wan & & Location & & $\begin{array}{l}\text { Peru } \\
\text { Tirta }\end{array}$ & $\begin{array}{l}\text { mahan Bumi } \\
\text { Nirwana }\end{array}$ \\
\hline Jabatan & & kang & & Work Proje & & $\begin{array}{l}\text { Men } \\
\text { Gen }\end{array}$ & $\begin{array}{l}\text { lasang } \\
\text { eng }\end{array}$ \\
\hline No & $\begin{array}{c}\text { Urutan } \\
\text { Elemen } \\
\text { Pekerjaan }\end{array}$ & $\begin{array}{c}\text { Potential } \\
\text { Hazard }\end{array}$ & Consequences & Likelihood & $\begin{array}{c}\text { Level } \\
\text { of } \\
\text { Risk }\end{array}$ & Comment & $\begin{array}{c}\text { Safety } \\
\text { Indication }\end{array}$ \\
\hline $\mathbf{1}$ & $\begin{array}{l}\text { Menentukan } \\
\text { Posisi } \\
\text { Tangga }\end{array}$ & Tergelincir & 15 & 3 & 45 & Priority 3 & $\begin{array}{c}\text { Pengecekan } \\
\text { Tangga }\end{array}$ \\
\hline 2 & $\begin{array}{l}\text { Memasang } \\
\text { Tangga }\end{array}$ & $\begin{array}{l}\text { Tergelinci, } \\
\text { Tertimpa } \\
\text { Material }\end{array}$ & 15 & 3 & 45 & Priority 3 & $\begin{array}{l}\text { Dipasang di } \\
\text { Tempat } \\
\text { vang Stabil }\end{array}$ \\
\hline 3 & $\begin{array}{c}\text { Menaiki } \\
\text { Tangga }\end{array}$ & $\begin{array}{l}\text { Tergelinci, } \\
\text { Iritasi } \\
\text { Mata, } \\
\text { Terjatuh }\end{array}$ & 25 & 10 & 250 & Priority 1 & $\begin{array}{c}\text { Memastikan } \\
\text { Alas Kaki } \\
\text { Aman }\end{array}$ \\
\hline 4 & $\begin{array}{l}\text { Menentukan } \\
\text { Titik } \\
\text { Pemasangan }\end{array}$ & Tergores & 5 & 3 & 15 & Acceptable & $\begin{array}{c}\text { Memastikan } \\
\text { Alas Kaki } \\
\text { Aman }\end{array}$ \\
\hline 5 & $\begin{array}{l}\text { Mengangkat } \\
\text { Genteng }\end{array}$ & Tergores & 5 & 10 & 150 & Subtantial & $\begin{array}{c}\text { Memakai } \\
\text { Sarung } \\
\text { Tangan Kain }\end{array}$ \\
\hline 6 & $\begin{array}{c}\text { Menuju } \\
\text { Titik } \\
\text { Pemasangan }\end{array}$ & Tergelincir & 25 & 3 & 75 & Subtantial & $\begin{array}{l}\text { Memastikan } \\
\text { Alas Kaki } \\
\text { Aman }\end{array}$ \\
\hline 7 & $\begin{array}{l}\text { Mengangkat } \\
\text { Genteng }\end{array}$ & $\begin{array}{c}\text { Tergelincir, } \\
\text { Tergores, } \\
\text { Terjatuh, } \\
\text { Cedera }\end{array}$ & 25 & 10 & 250 & Priority 1 & $\begin{array}{c}\text { Memakai } \\
\text { Sarung } \\
\text { Tangan, } \\
\text { Memastikan } \\
\text { Alas Kaki } \\
\text { Aman, Posisi } \\
\text { Kerja } \\
\text { Ergonomis }\end{array}$ \\
\hline 8 & $\begin{array}{l}\text { Mengambiil } \\
\text { Genteng }\end{array}$ & Tergores & 5 & 3 & 15 & Acceptable & $\begin{array}{c}\text { Memakai } \\
\text { Sarung } \\
\text { Tangan } \\
\text { Kain }\end{array}$ \\
\hline 9 & $\begin{array}{l}\text { Memasang } \\
\text { Genteng }\end{array}$ & Cedera & 15 & 6 & 90 & Subtantial & $\begin{array}{c}\text { Memastikan } \\
\text { Posisi } \\
\text { Memasang } \\
\text { Ergonomis }\end{array}$ \\
\hline 10 & $\begin{array}{l}\text { Mengangkat } \\
\text { Adukan } \\
\text { Semen }\end{array}$ & Terkilir & 15 & 10 & 150 & Subtantial & $\begin{array}{c}\text { Memastikan } \\
\text { Posisi Kerja } \\
\text { Ergonomis }\end{array}$ \\
\hline 11 & $\begin{array}{l}\text { Menyemen } \\
\text { Genteng } \\
\text { yang Sudah }\end{array}$ & $\begin{array}{l}\text { Terkilir, } \\
\text { Tergores }\end{array}$ & 15 & 10 & 150 & Subtantial & $\begin{array}{c}\text { Memastikan } \\
\text { Posisi Kerja } \\
\text { Ergonomis }\end{array}$ \\
\hline
\end{tabular}




\begin{tabular}{ccccccc}
\hline \multicolumn{3}{c}{ Dipasang } & & & & \\
\hline Mengecek & Terjepit & 15 & 10 & 150 & Subtantial & Memakai \\
& Kerapatan & Material & & & Sarung \\
& Semen pada & & & Tangan \\
Genteng & & & & \\
\hline
\end{tabular}

Dilihat pada Tabel 4 bahwa nilai consequences dan nilai likelihood didapat berdasarkan kejadian lapangan dan di konversi berdasarkan teori yang terdapat pada Tabel 2 dan Tabel 3 lalu untuk nilai level of risk diperoleh dari hasil kali nilai consequences dan nilai likelihood sebagai contoh untuk urutan elemen pekerjaan nomor 1 yaitu elemen pekerjaan "menentukan posisi tangga" dengan perhitungan $15 \times 3=45$ dimana level of risk ini asuk kategori Priority 3

2. Data Perbandingan Sebelum dan Sesudah Perbaikan dengan JHA

a. Data Kecelakaan Kerja Sebelum

Dilihat dari Tabel 5 bahwa kecelakaan kerja membuat kerugian berupa akibat - akibat yang ditimbulkan dibawah ini:

Tabel 5

Data Kecelakaan Kerja Sebelum Implementasi JHA Bulan Februari - Maret

\begin{tabular}{llccccc}
\multicolumn{7}{c}{ Bulan Februari - Maret } \\
\hline \multirow{2}{*}{ No } & \multirow{2}{*}{ Jenis Kecelakaan } & \multirow{2}{*}{ Jumlah } & \multicolumn{5}{c}{ Akibat } \\
\cline { 3 - 7 } Periode \\
\hline $\mathbf{1}$ & Tergelincir & 18 & 14 & 4 & 0 & 0 \\
\hline $\mathbf{2}$ & Tertimpa Material & 12 & 7 & 5 & 0 & 0 \\
\hline $\mathbf{3}$ & Tergores & 127 & 125 & 2 & 0 & 0 \\
\hline $\mathbf{4}$ & Terkilir & 48 & 39 & 9 & 0 & 0 \\
\hline $\mathbf{5}$ & Cedera & 24 & 13 & 9 & 0 & 0 \\
\hline $\mathbf{6}$ & Terjepit Material & 36 & 36 & 0 & 0 & 0 \\
\hline $\mathbf{7}$ & Terjatuh & 36 & 2 & 3 & 0 & 0 \\
\hline $\mathbf{8}$ & Patah $\mathrm{Tu}$ & 0 & 0 & 0 & 0 & 0 \\
\hline $\mathbf{9}$ & Iritasi $\mathrm{M} \boldsymbol{c}$ & 37 & 37 & 0 & 0 & 0 \\
\hline \multirow{2}{*}{ M } & & & & & & \\
\end{tabular}

b. Data Kecelakaan Kerja Sesudah

Tabel 6

Data Kecelakaan Kerja Setelah Implementasi JHA Bulan April

\begin{tabular}{llccccc}
\hline \multicolumn{7}{c}{ Bulan April } \\
\hline \multirow{2}{*}{ No } & \multirow{2}{*}{ Jenis Kecelakaan } & \multirow{2}{*}{ Jumlah } & \multicolumn{4}{c}{ Akibat } \\
\cline { 3 - 7 } & & Luka Ringan & Luka Berat & Cacat & Kematian \\
\hline $\mathbf{1}$ & Tergelincir & 3 & 2 & 1 & 0 & 0 \\
\hline $\mathbf{2}$ & Tertimpa Material & 1 & 1 & 0 & 0 & 0 \\
\hline $\mathbf{3}$ & Tergores & 7 & 4 & 3 & 0 & 0 \\
\hline $\mathbf{4}$ & Terkilir & 1 & 1 & 0 & 0 & 0 \\
\hline $\mathbf{5}$ & Cedera & 0 & 0 & 0 & 0 & 0 \\
\hline
\end{tabular}


Analisis Bahaya dan Resiko pada Pengerjaan Pemasangan Genteng Di PT. Bumi Rajawali Sentosa Menggunakan Metode Job Hazard Analysis

\begin{tabular}{lllllll}
\hline $\mathbf{6}$ & Terjepit Material & 2 & 2 & 0 & 0 & 0 \\
\hline $\mathbf{7}$ & Terjatuh & 0 & 0 & 0 & 0 & 0 \\
\hline $\mathbf{8}$ & Patah $\mathrm{Tu}$ l & 0 & 0 & 0 & 0 & 0 \\
\hline $\mathbf{9}$ & Iritasi $\mathrm{M} \boldsymbol{c}$ & 1 & 1 & 0 & 0 & 0 \\
\hline
\end{tabular}

Dilihat dari Tabel 6 bahwa setelah adanya implementasi JHA terdapat pengurangan jumlah kejadian kerja sehingga dapat disimpulkan bahwa metode JHA dapat mengurangi kecelakaan kerja.

3. Uji Correlation Coefficient Menggunakan Microsoft Excel

Berdasarkan persamaan rumus diperoleh hasil uji correlation coefficient yang dapat dilihat pada gambar 6 dibawah ini:

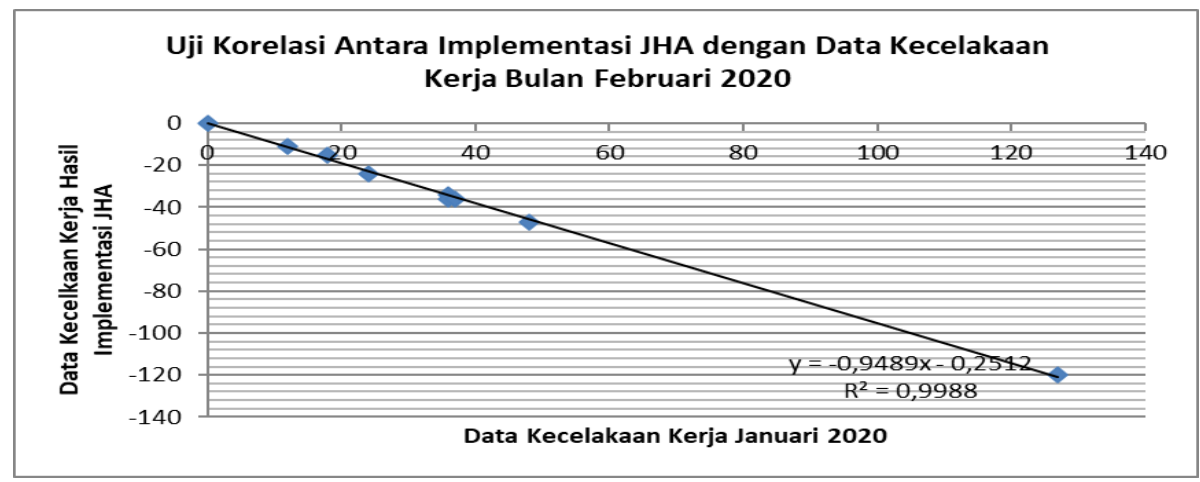

\section{Gambar 1}

Grafik uji Korelasi Implementasi JHA Terhadap Penurunan Kecelakaan Kerja Bulan Februari 2020

\section{Analisis}

1. Penyusunan JHA (Job Hazard Analysis)

Pada penyusunan elemen kerja ada dua poin yang menjadi parameter yaitu potential hazard, level of risk dan safety indication. Potential hazard berfungsi untuk mengidentifikasi potensi bahaya (Purnamasari, 2020) yang akan timbul di setiap elemen kerja, level of risk berfungsi untuk prioritas penanganan dari masing masing potensi hazard yang telah diketahui sebelumnya dan safety indication digunakan sebagai alat analisis yang digunakan dalam mengurangi dan mengeliminasi berdasarkan kondisi existing sehingga didapatkan hasil data kecelakaan kerja yang lebih kecil atau tidak ada lagi daripada data kecelakaan kerja sebelum adanya analisis tersebut yang merupakan salah satu proses dari metode JHA (Job Hazard Analysis) untuk lebih jelasnya dapat dilihat pada Kesalahan Sumber referensi tidak ditemukan.

2. Uji Correlation Coefficient

Pengaruh dari implementasi JHA haruslah diuji secara empirik untuk membuktikan bahwa adanya pengaruh terhadap implementasi JHA dan memberikan dampak positif terhadap pengurangan data kecelakaan kerja yang terjadi pada proses pekerjaan memasang genteng dari hasil uji pengaruh 
implementasi JHA menunjukkan nilai korelasi sebesar 0.999 yang termasuk dalam korelasi sangat kuat dimana menandakan bahwa implementasi JHA sangatlah berikatan kuat dengan adanya pengurangan terjadinya kecelakaan kerja pada proses pemsangan genteng di PT. Rajawali Sentosa.

\section{Pembahasan}

Kecelakaan kerja dapat menyebabkan kerugian baik secara fisik maupun finansial sehingga diperlukan analisis secara pasti untuk mengatasi tingkat kecelakaan kerja sehingga dapat secara penuh dihilangkan, pada kasus pemasangan genteng di PT. Bumi Rajawali Sentosa data kecelakaan kerja pada bulan Februari Maret 2020 menunjukan tingkat terjadinya kecelakaan kerja sangat sering, maka diperlukan solusi yang tepat, metode JHA menjadi solusi untuk penanganan kejadian kecelakaan kerja tersebut dikarenakan metode JHA dapat mengidentifikasi secara detail dan memberikan informasi berupa potential hazard, level of risk, safety indication yang telah di deskripsikan secara detail pada Kesalahan! Sumber referensi tidak ditemukan., setelah implementasi dilakukan pengujian korelasi untuk memastikan bahwa metode yang digunakan akan berkorelasi secara jangka panjang dan menurunkan tingkat kecelakaan kerja apabila diterapkan secara teratur dan sesuai pedoman JHA yang telah dibuat maka dari hasil analisis didapatkan nilai $r$ sebesar 0.999 yang menunjukan hubungan yang kuat.

Pada penyusunan elemen kerja ada dua poin yang menjadi parameter yaitu potential hazard, level of risk dan safety indication (Hariyanto, 2010). potential hazard berfungsi untuk mengidentifikasi potensi bahaya yang akan timbul di setiap elemen kerja, level of risk berfungsi untuk prioritas penanganan dari masing masing potensi hazard yang telah diketahui sebelumnya dan safety indication digunakan sebagai alat analisis yang digunakan dalam mengurangi dan mengeliminasi berdasarkan kondisi existing sehingga didapatkan hasil data kecelakaan kerja yang lebih kecil atau tidak ada lagi daripada data kecelakaan kerja sebelum adanya analisis tersebut yang merupakan salah satu proses dari metode JHA (Job Hazard Analysis).

\section{Kesimpulan}

Summary analisis bahaya dengan metode JHA per elemen pekerjaan yaitu untuk menentukan posisi tangga didapatkan kategori safety priority 3 dengan pencegahan dilakukan pengecekan tangga, untuk memasang tangga didapatkan kategori safety priority 3 dengan pencegahan dipasang di tempat stabil, untuk menaiki tangga didapatkan kategori safety priority 1 dengan pencegahan memastikan alas kaki aman, untuk menentukan titik pemasangan genteng didapatkan kategori safety acceptable dengan pencegahan memastikan alas kaki aman, untuk memasang genteng didapatkan kategori safety subtantial dengan pencegahan memakai sarung tangan kain, untuk menuju titik pemasangan genteng didapatkan kategori safety subtantial dengan pencegahan memastikan alas kaki aman, untuk mengambil genteng didapatkan kategori safety priority 1 dengan pencegahan memastikan alas kaki aman, untuk memasang 
Analisis Bahaya dan Resiko pada Pengerjaan Pemasangan Genteng Di PT. Bumi Rajawali Sentosa Menggunakan Metode Job Hazard Analysis

genteng didapatkan kategori safety acceptable dengan pencegahan memakai sarung tangan kain, untuk mengangkat adukan semen didapatkan kategori safety subtantial dengan pencegahan memastikan posisi memasang ergonomis. 


\section{BIBLIOGRAFI}

Dasar, A. Konsep, \& Operasional, Batasan. (1988). A. Metode Penelitian. Google Scholar

Dharmawirawan, Dimas Ari, \& Modjo, Robiana. (2012). Identifikasi Bahaya Keselamatan dan Kesehatan Kerja pada Penangkapan Ikan Nelayan Muroami. Kesmas: Jurnal Kesehatan Masyarakat Nasional (National Public Health Journal), 6(4), 185-192. Google Scholar

Haidi, Hafidz, \& Abdullah, Rijal. (2020). Upaya Meminimalisir Kecelakaan Kerja di Area Penambangan PT. Adaro Services Job Site Binungan, Berau Provinsi Kalimantan Timur. Bina Tambang, 5(2), 77-87. Google Scholar

Hariyanto, Asep. (2010). Strategi penanganan kawasan kumuh sebagai upaya menciptakan lingkungan perumahan dan permukiman yang sehat (contoh kasus: kota Pangkalpinang). Jurnal Perencanaan Wilayah Dan Kota UNISBA, 7(2), pp11. Google Scholar

Istanti, Fenny Novia, Tama, Ishardita Pambudi, \& Azlia, Wifqi. (2019). Analisis Keselamatan Dan Kesehatan Kerja Pada Pembuatan Pipa Penstock Dengan Menggunakan Job Hazard Analysis. Jurnal Rekayasa Dan Manajemen Sistem Industri, 7(4), p23-34. Google Scholar

Li, Weijun, Zhang, Laibin, \& Liang, Wei. (2016). Job hazard dynamic assessment for non-routine tasks in gas transmission station. Journal of Loss Prevention in the Process Industries, 44, 459-464. Google Scholar

Marbun, Riniwati Juliana, Puspitasari, Nia Budi, \& Budiawan, Wiwik. (2015). Identifikasi dan Analisis Risiko Keselamatan dan Kesehatan Kerja pada Area Produksi PT. Pelita Cengkareng Paper. Industrial Engineering Online Journal, 4(4). Google Scholar

Martaningtyas, M., \& Ariesyady, H. D. (2018). Identifikasi bahaya dan analisis risiko pada jaringan pipa transmisi crude oil di PT. X. Jurnal Teknik Lingkungan, 24(2), 12-22. Google Scholar

Phuspa, Sisca Mayang, \& Rudyarti, Edwina. (2017). The Relationship of Belief, Experience, Knowledge, and Attitudes Toward Safety Behavior of Construction Workers at University X Ponorogo. Indonesian Journal for Health Sciences, 1(2), 34-41. Google Scholar

Purnamasari, Aulia Widya. (2020). Identifikasi Potensi Bahaya Keselamatan dan Kesehatan Kerja pada Proses Produksi. HIGEIA (Journal of Public Health Research and Development), 4(Special 1), 89-100. Google Scholar

Ramdan, Iwan M., \& Rahman, Abd. (2018). Analisis risiko Kesehatan dan Keselamatan Kerja (K3) pada perawat. Jurnal Keperawatan Padjadjaran, 5(3). Google Scholar 
Analisis Bahaya dan Resiko pada Pengerjaan Pemasangan Genteng Di PT. Bumi Rajawali Sentosa Menggunakan Metode Job Hazard Analysis

Rosdiana, Nova, Anggraeni, Shanti Kirana, \& Umyati, Ani. (2017). Identifikasi Risiko Kecelakaan Kerja Pada Area Produksi Proyek Jembatan Dengan Metode Job Safety Analysis (JSA). Jurnal Teknik Industri Untirta. Google Scholar

Sugiyanto, Gito, \& Santi, Mina Yumei. (2015). Karakteristik Kecelakaan Lalu Lintas dan Pendidikan Keselamatan Berlalulintas Sejak Usia Dini: Studi Kasus di Kabupaten Purbalingga. Semesta Teknika, 18(1), 65-75. Google Scholar

Swartz, George. (2002). Job hazard analysis. Professional Safety, 47(11), 27. Google Scholar

Syarif, Rusli. (2010). Manajemen sumber daya manusia. Cetakan Ketiga. Jakarta: Penerbit Gramedia Pustaka Utama. Google Scholar

\section{Copyright holder:}

Bhuana Satria Gigantara (2021)

First publication right:

Syntax Literate: Jurnal Ilmiah Indonesia

This article is licensed under: 